\title{
Mathematics Teachers' Problem-Solving Knowledge, Practices and Engagement among Public Junior High Schools in Berekum West, Ghana
}

\author{
Collins Asoma \\ Orcid: https://orcid.org/0000-0001-8760-682X \\ Department of Mathematics and ICT, Berekum College of Education, Ghana \\ Email: collay@becoled.edu.gh \\ Clement Ayarebilla Ali, PhD \\ Orcid: http://orcid.org/0000-0002-3268-6452 \\ Department of Basic Education, University of Education, Winneba, Ghana \\ Email: ayarebilla@yahoo.com \\ Nixon Saba Adzifome \\ Orcid: https://orcid.org/0000-0002-4428-8793 \\ Department of Basic Education, University of Education, Winneba, Ghana \\ Email: adzisaba@yahoo.com \\ Appiah-Kubi Eric \\ Orcid: https://orcid.org/0000-0003-4632-2438 \\ Department of Education, Berekum College of Education, Ghana \\ Email: appiahkubi0004@gmail.com \\ Corresponding Mail: collay@becoled.edu.gh
}

\footnotetext{
Copyright resides with the author(s) in terms of the Creative Commons Attribution CC BY-NC 4.0. The users may copy, distribute, transmit and adapt the work, but must recognize the author(s) and the East African Journal of Education and Social Sciences
}

\begin{abstract}
This study focused on Mathematics teachers' problem-solving knowledge, practices and students' engagement based on Polya's problem-solving model, using the sequential explanatory research design. The study adopted the census technique to collect data from 80 Junior High School Mathematics teachers for the quantitative phase. Thereafter, five Mathematics teachers were selected from the 80 teachers for interview to supplement quantitative findings. The quantitative data was analysed using means and standard deviations while the qualitative data was transcribed and analysed thematically. The results demonstrated that even though Mathematics teachers had knowledge, they moderately used problem-solving instructional strategies in their lessons. They applied manipulative materials other than the standard procedures espoused in problem-solving techniques. Therefore, the researchers recommend a new paradigm of training teachers on problemsolving techniques for Mathematics instruction.
\end{abstract}

Keywords: Mathematics; knowledge; problem-solving; Polya's Model; sequential explanatory design

How to cite: Asoma, C., Ali, C. A., Adzifome, N. S., Eric, A. (2022). Mathematics Teachers' Problem-Solving Knowledge, Practices and Engagement among Public Junior High Schools in Berekum West, Ghana. East African Journal of Education and Social Sciences 3(1), 29-37. Doi: https://doi.org/10.46606/eajess2022v03i01.0143.

\section{Introduction}

Problem-solving is viewed as addressing everyday tasks that challenge the solver to use their predictive and analytical skills (Pertersen (2016). In this situation, the problem solver must use prediction and analysis to find a solution to the problem. Problem-solving is very important in the study of Mathematics. It offers opportunities for 
students to engage in meaningful Mathematical discourse, including analyzing various representations and justifications for their solutions. Problem-solving instructional practices enable students to become active participants in the learning process and engage teachers to participate actively as learners in the classroom.

In this context, Bay (2000) explains teaching via problem-solving as a method by which Mathematics teachers may provide more meaningful instruction. Advancing his argument, the author further explains that teaching via problem-solving means application of Mathematics content using problem-solving strategies with the right tools. Students develop, extend and enrich their understanding by solving problems (Hieber \& Wearne, 2003). Teaching through problem-solving prepares students for a life full of able-mindedness. It also helps students develop confidence as problem solvers and become Mathematical risk-takers (Tratton \& Midgett, 2001).

Besides, Van de Walle (2007) equally observes that the teaching of Mathematics through a problemsolving approach helps teachers to engage students fully in essential Mathematics learning. This implies that problem-solving permeates every Mathematics task and as a generic skill, it involves independent thinking and critical analysis of issues which is important for life-long learning. It is therefore desirable that students develop Mathematical problem-solving skills at the basic school as a sign of readiness for life-long learning and the job market.

The problem of teachers' lack of knowledge and skills in using effective and efficient problem-solving techniques in teaching Mathematics still persists in Ghana (Mereku, 2015). Mereku argues that teachers are failing to help students develop the ability to solve problems in Ghanaian basic schools. In order to improve upon the techniques, teachers need to incorporate into Polya's model the cardinal tenets of teaching via problem-solving. This is a method by which Mathematics teachers provide more meaningful Mathematics instruction. George Polya (1887-1985) was a Mathematical giant who introduced classical analysis into problem-solving in the twentieth century. In such a method, students should develop, extend and enrich their understanding by solving problems (Hieber, 2003). This helps students to develop confidence and become mathematically proficient. Cai and Lester (2012) observed that teaching through problemsolving promotes conceptual understanding, develops the capacity to reason and communicates
Mathematically, cultivating interest and curiosity in Mathematics. According to Polya's model, problemsolving can be viewed as an activity involving a variety of skills. Problem-solving is supposed to be a practical art: a lesson taught and learned. It is about the ability of the child to make use of previous knowledge and apply it in a new situation (Polya, 1945).

The child's ability to remember basic arithmetic skills, how and when to incorporate them into a new situation and the ability to do so are three distinct skills. The child may have all three skills that facilitate problem-solving; however, a child's inability to use one of the skills does not mean that he or she understands the problem. It may mean that the child's learning style has not been adequately addressed (Polya, 1954). Similarly, the fact that the child can perform the procedures in isolation, does not mean that he or she has the knowledge to apply them or can interpret the numbers involved (Bley \& Thornton, 2001). A good problem is one of the modifications that can be made for students with different skills, abilities and learning styles. Therefore, teachers are encouraged to use multiple solutions and multiple methods in a classroom, which will promote problem-solving skills.

The theoretical model was adopted from Polya's problem-solving approach, which states that problem-solving can be seen as an activity comprising a variety of skills (Polya, 1945). This was infused with teaching via problem-solving tenets, as discussed below.

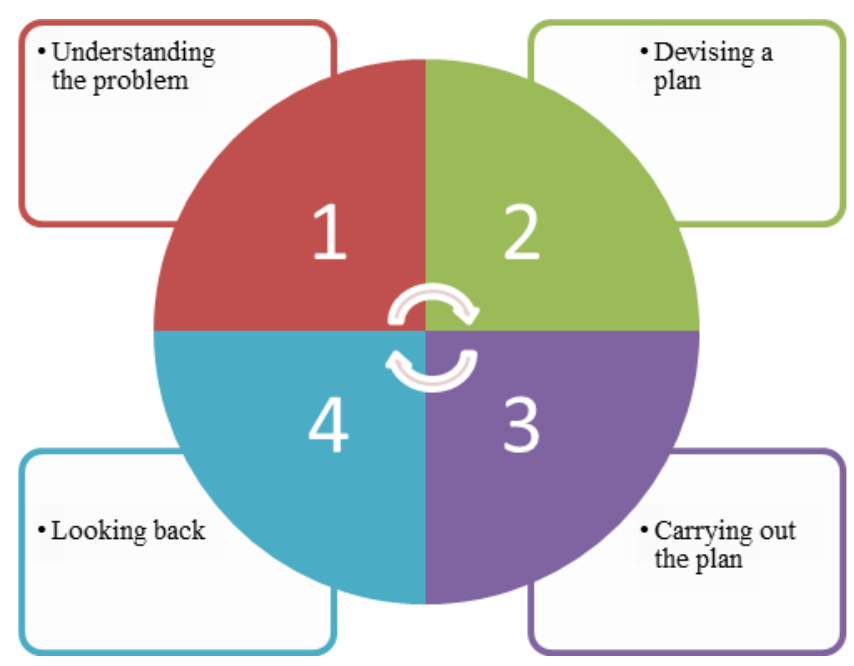

Figure 1: Polya's problem-solving model (Polya, 1945)

Figure 1 describes Polya's the problem-solving model. In stage one, teachers find, show, grasp 
and/or estimate conditions, assumptions, information and restate the problem in their own words, pictures, diagrams or illustrations. In the second stage, teachers guess and check, draw pictures or graphs. In the third stage, teachers use manipulatives or models, eliminate possibilities, use cases and solve equivalent problems. In the fourth stage, teachers measure, assess and evaluate the outcomes of the solutions (Polya, 1945). In each state, teachers teach for, about and through problem-solving. Teaching for problem-solving involves students learning Mathematical content to apply it to solve practical problems (Webb \& Sepeng, 2012; Lester, 2013). Teaching about problem-solving means instruction about the processes (Lester, 2013). Teaching through problemsolving means making sense of Mathematical procedures (Anderson, 2009).

The successful implementation of a problem-solving Mathematics curriculum depends on the teacher's conception and experiences. Moreover, current technology and scientific advancement, being experienced worldwide, require that Ghanaian learners are taught to go beyond low-level comprehension and mere memorization of facts and formulae, if they are to become problem solvers of the future. Teachers should therefore be adequately equipped to develop high-level mathematical thinking skills in their students or learners. The acquisition of problem-solving skills and the deepening of the students' problem-solving skills depend on the teacher. Specifically, the teacher has to make a good choice, which includes, choosing appropriate materials that could engage students, selecting appropriate methods of teaching, providing an enabling environment for students to explore, taking appropriate decisions to avoid risks and sharing failures and successes in real practices. A teacher's role in developing problem-solving skills in Mathematics is drastically transformed from his or her traditional role as a source of knowledge and authority to that of a guide and facilitator.

Skills in problem-solving are applied in various spheres of human endeavour. They are applied in commerce, industry or science. Because of this, problem-solving is recommended as a powerful instructional tool in Mathematics education (Roberts, Sharma, Britton \& New, 2009). Teachers can equip students with problem-solving skills to enable them to solve real-life problems only if teachers' practices are tailored towards achieving the objectives of problem-solving as delineated by the curriculum. A careful look at the Junior High School Mathematics curriculum in Ghana shows that sufficient provision has been made in the curriculum documents to guide teachers to use problem-solving in Mathematics lesson delivery, but it is not known whether teachers make the same sense of it.

Again, limited knowledge of teachers in problemsolving influences its use in the Mathematics classroom. It is against this background that this sought to answer the following research questions:

1. What is mathematics teachers' perceived knowledge for teaching problem-solving among public junior high schools in Berekum West district?

2. Which instructional strategies do mathematics teachers employ for teaching problem-solving among Public Junior High Schools in Berekum West District?

3. How do Mathematics Teachers engage pupils in Problem-Solving among public junior high schools in Berekum West district?

\section{Methodology of the Study}

\section{Research Design}

This study adopted both quantitative and qualitative approaches because the findings from the qualitative data are to enrich the findings from the quantitative data (Mason, 2006) in order to generate new knowledge effectively (Creswell, 2009). Morrison (2012) outlines that adopting both quantitative and qualitative methods (two traditional approaches) give an in-depth understanding of a phenomenon.

A sequential explanatory research design was used for the study. According to Creswell (2017), sequential explanatory design is one in which the researcher conducts quantitative research first, analyzes the results and then uses qualitative research to expand the findings. One of the strengths of using the sequential explanatory research design is that the two phases (quantitative and qualitative) make it straightforward to implement. Because the researcher conducts the two methods separately and collects one piece of data at a time, the final report from the study provides a clear delineation for readers. Therefore, to explore a teacher's perceived knowledge, instructional strategies and how they engage pupils, the researchers adopted the sequential explanatory design. In this study, the researchers first collected the numeric data (quantitative) and analysed it. The 
qualitative data and their analysis refined and explained those statistics results by exploring participants' views more deeply (Creswell, 2009).

\section{Population and Sampling}

Kusi (2012) defines a population as a group of individuals or people with the same characteristics as the researcher and in whom the researcher is interested. The population of this study consisted of all the eighty (80) Mathematics teachers in the Berekum West District. The researchers adopted the census technique for the quantitative phase. Thereafter, five teachers were selected conveniently from the eighty (80) Mathematics teachers and were interviewed to confirm their perceived knowledge and practices of problem-solving. The census was used because the researchers sought to establish the knowledge and skills of all the Mathematics teachers in the District. Again, the researchers conveniently selected a sample of one female and four male teachers from among the eighty (80) teachers for the interview section.

\section{Instruments}

The main instruments of data collection were a structured questionnaire for quantitative data and an interview guide for qualitative data. The two instruments allowed triangulation in order to increase the credibility of findings.

The Cronbach's alpha coefficient scale of above 0.7 which is desirable in a study (Abel, Buff \& Burr, 2016) was ensured prior to data collection. The researchers ensured that the constructions of the data collection instruments were well structured and aligned with the research questions. The quantitative data collected was analysed using means and standard deviations while the qualitative data were transcribed and analysed thematically. The ethical considerations of permission, confidentiality and anonymity were duly sought and satisfied (Kusi, 2012). Trustworthiness of this study was enhanced by including participants' differing viewpoints, giving more credibility to the findings.

\section{Data Collection Procedures}

The researchers presented an introductory letter to the District Education Directorate for permission to undertake the study. The letter explained reasons for the study and assured confidentiality of responses (Kusi, 2012).The District Directorate forwarded and authorized letters to the heads of schools for them to allow the researchers undertake the study. Thereafter, the researchers discussed the time schedules and appointments with the participating teachers so that the processes did not interfere with teaching and learning. After issuing the questionnaire, the interview guide followed.

\section{Statistical Treatment of Data}

Data was analyzed using descriptive statistics (mean scores and standard deviation). Qualitative data was thematically analyzed.

\section{Findings and Discussions}

Research Question 1: What is mathematics teachers' perceived knowledge for teaching problem-solving among public junior high schools in Berekum West District?

In view of the 4-point Likert scale used, which makes the average/fair score to be $2.5([1+2+3+4] \div 4)$, the determination of the level of Mathematics teachers' perceived knowledge on problem-solving was done using means and standard deviations. The statistical mean of less than 2.50 indicated low perceived knowledge, between 2.50 and 3.50 indicated fair perceived knowledge and greater than 3.50 indicated good perceived knowledge. The analysis of Research Question 1 is found on Table 1.

Table 1: Descriptive Statistics on Mathematics Teachers' Perceived Knowledge on Problem-Solving

\begin{tabular}{|c|c|c|c|}
\hline Statements on Perceived Knowledge & Mean & Std. Dev & $\begin{array}{l}\text { Perceived } \\
\text { Knowledge }\end{array}$ \\
\hline Mathematics problems should task pupils to reason logically and critically & 3.68 & 0.47 & Good Knowledge \\
\hline $\begin{array}{l}\text { Mathematics problems should have connection with pupils' real-life } \\
\text { situation }\end{array}$ & 3.61 & 0.54 & Good Knowledge \\
\hline $\begin{array}{l}\text { Mathematics problem should challenge pupils to apply daily skills in solving } \\
\text { it }\end{array}$ & 3.60 & 0.52 & Good Knowledge \\
\hline Mathematics should guide pupils to self-develop strategies & 3.53 & 0.50 & Good Knowledge \\
\hline Problem-solving involves tasks that challenge pupils' ability & 3.39 & 0.59 & Fair Knowledge \\
\hline $\begin{array}{l}\text { Mathematics problem should require pupils to conjecture their strategies in } \\
\text { solving it }\end{array}$ & 3.20 & 0.79 & Fair Knowledge \\
\hline Overall Perceived Knowledge & 3.50 & 0.57 & Good Knowledge \\
\hline
\end{tabular}


Table 1 revealed that Mathematics teachers perceived the problem-solving should involve tasking learners to reason logically and critically $(M=3.68$, SD=0.47) than problems having a connection with learners' real-life situation $(M=3.61, S D=0.54)$. Mathematics problems that challenge the learner to apply their daily skills in solving it ( $M=3.60, S D=0.52)$ was considered good.

This notwithstanding, Mathematics teachers' perception of problem-solving is mere Mathematics lessons that should guide learners. Instead of obtaining nearly 4.00, they conceived problemsolving to be Mathematics lessons that should guide learners to develop strategies in solving problems $(\mathrm{M}=3.53, \mathrm{SD}=0.50)$, Mathematical problems involving tasks that challenge the learners' ability ( $M$ $=2.80, \mathrm{SD}=0.59)$, and Mathematical problems requiring learners to conjecture their strategies in solving it $(M=3.20, S D=0.79)$ components. Overall, Mathematics teachers' perception of the general knowledge yielded a mean of $3.40(S D=0.57)$ falling slightly below 4.00. Therefore, on the whole, one can observe that the Mathematics teachers' perceived knowledge as an embodiment of problem-solving and that ensured fair perceived knowledge in problem-solving.

Five teachers were interviewed. The abbreviation TR followed by a number in the right connotes a teacher. As a follow up on Research Question one, respondents were asked to explain what they think problem-solving is all about.

This question was meant to solicit the teachers' views of what they know about problem-solving. From the responses, it was clear that almost all the teachers had a good perceived knowledge about problem-solving as follows. "Ah, problem-solving is a way of helping pupils to devise their own strategies to find answers to problems that they encounter in their daily life" (TR1, Interviewed data, 2020). "Mathematics problem-solving has to do with the efforts that one makes to find a solution to a problem that probably you might have not met before" (TR 2, Interviewed data, 2020)." Problemsolving is all about giving Mathematics problem to children to think and reason very well before getting an answer" (TR 3, Interviewed data, 2020). "From the experience I have, problem-solving has to do with word problem where children are required to think and sometimes work in a group to provide a solution to an unsolved problem" (TR 4, Interviewed data, 2020). "Problem-solving is a process of finding a solution to a given problem" (TR5, Interviewed data, 2020).

The next question the researcher asked was to find out when and how the teachers came to realise problem-solving as a necessary focus in teaching Mathematics. The responses from the teachers' indicated that most of them heard of Problemsolving concept at their training colleges and at some workshops they attended. However, none of them had attended any workshop on problemsolving for the past few years:

Through various books I've read, I've learned about problem-solving as an emphasis in teaching Mathematics. I got to know at college that problem-solving is one of the best approaches to evaluating students' application of Mathematics. So as a teacher I try to relate my lessons to students' daily life" (TR 1 Interviewed data, 2020).

"I learned that problem-solving is one of the techniques to assess a child's comprehension. I learnt that way back at College, about 10 years ago and I sometimes use it in my lessons" (TR 2 Interviewed data, 2020). "From the time I was in training college, I saw problem-solving as an emphasis in teaching Mathematics. We were taught and when I became a teacher, I sometimes try to also use problem-solving in my lessons" (TR 3 Interviewed data, 2020). "A workshop I attended a few years ago introduced me to problem-solving. I got to know that problem-solving challenges children thinking so when I want to children to think deeply, I use problem-solving" (TR 4 Interviewed data, 2020). "I heard problem-solving from college and also from a workshop. It gives an in-depth understanding of both conceptual and procedural knowledge to pupils" (TR5 Interview data, 2020). From these excerpts, the researcher deduced that most of the JHS Mathematics teachers have heard about problem-solving and they have good perceived knowledge about what it is all about. For example, the definitions they gave were good.

The overall results from the questionnaire in table 1 revealed that Berekum West JHS Mathematics teachers had good knowledge ( $M=3.50, S D=0.57$ ) of problem-solving. Earlier studies conducted by Andrews and Xenofontos (2014), Mereku (2015), Mclntosh, Jarrett \& Peixotto, 2000), attested that teacher lack expert knowledge in the area of problem-solving therefore, they do not teach 
problem-solving in Mathematics. This is against the findings of this study.

Research Question 2: Which instructional strategies do mathematics teachers employ for teaching problem-solving among Public Junior High Schools in Berekum West District?

The second research question dwelled on the instructional strategies that were employed by
Mathematics teachers in teaching problem-solving. In ascertaining the extent of usage of the problemsolving instructional techniques, mean scores and standard deviation were used such that mean $<2.50$ indicated rarely used, $2.50 \leq$ mean $<3.50$ indicated moderately used, and mean $\geq 3.50$ indicated highly used. The results on the instructional techniques and the general level of usage are presented in Table 2.

Table 2: Teachers' Knowledge and Practices

\begin{tabular}{llll}
\hline Techniques & Mean & Std. Dev. & Knowledge/Practice \\
\hline Task base Instruction & 3.53 & 0.55 & High \\
Cooperative Learning Technique & 3.52 & 0.68 & High \\
Project Work Technique & 3.43 & 0.70 & Moderate \\
Guided Discovery Technique & 3.31 & 0.94 & Moderate \\
Group Work Technique & 3.31 & 0.70 & Moderate \\
Assignment Technique & 3.29 & 0.59 & Moderate \\
Self-Instruction Technique & 3.16 & 0.75 & Moderate \\
Inquiry Learning Technique & 3.07 & 0.98 & Moderate \\
Computer Assisted Instruction & 2.47 & 0.91 & Low \\
Overall & 3.23 & 0.75 & Moderate \\
\hline
\end{tabular}

The information in Table 2 disclosed that there were several instructional techniques that Mathematics teachers employed in teaching Problem-Solving in Mathematics instruction. Particularly, the findings showed that task base instruction $(M=3.53$, $\mathrm{SD}=0.55)$ and cooperative learning technique $(M=3.52, S D=0.68)$ were indicated to be highly used as compared to project work $(M=3.43, S D=0.67)$, guided discovery technique $(M=3.31, S D=0.94)$, group work $(M=3.31, S D=0.70)$, assignment technique $(M=3.29, \quad S D=0.59)$, self-instruction $(M=3.16, S D=0.75)$ and inquiry learning technique $(M=3.16, \quad S D=0.75)$ were all moderately used. Computer-assisted learning technique ( $M=2.47$, $\mathrm{SD}=0.91$ ) was rarely used. Generally, the findings of the study revealed that Mathematics teachers moderately used all the problem-solving instructional techniques outlined in the study.

The interview was to solicit teachers' views on the extent to which the teachers applied problemsolving instructional strategies in their teaching. The following questions were asked: Do you use instructional strategies for teaching problemsolving? One of the teachers indicated that "I love to give students group work assignments and also I sometimes encourage students to guess their answers before solving it" (TR 1 Interviewed data, 2020). Another teacher indicated that "I discuss the problem with them using drawings and diagrams to illustrate. Then I lead students to solve the problem by asking leading questions. Finally, I help them to work backwards to be sure that the answer is correct" (TR 2 Interviewed data, 2020).

Another teacher revealed that "I have various ways of adopting problem-solving. For example, I use normal exercise being in the form of puzzles so that students can reason more and write few" (TR 3 Interviewed data, 2020). It was further indicated that:

In fact, I employ a range of techniques, including compiling a list, creating a chart or table, drawing a diagram, creating a model, reducing the problem and working backwards from a pattern. Sometimes, I even use a formula or equation or act out the problem situation, using guess and check (TR 4 Interviewed data, 2020).

Apart from that, one teacher revealed that "through shared responsibilities between teacher and students (democratic classroom), teachers gained knowledge and practices on problem-solving" (TR5 Interview data, 2020.

The next question was asked to find out from the teachers regarding some of the challenges in teaching Mathematics through problem-solving. The following excerpts are some of the views expressed by the respondents: "students prefer to be told 
Mathematics rather than to be guided by the teacher to explore and construct their understanding" (TR 1 Interviewed data, 2020). Another teacher expressed that "Teaching through problem-solving requires a lot of time and if time is not sufficient, it is better to teach Mathematics by telling" (TR 2 Interviewed data, 2020). It was further revealed that "teachers have inadequate subject matter knowledge, pedagogical content knowledge and personal problems" (TR 3 Interviewed data, 2020). "Some teachers lacked the requisite knowledge, skills and expertise for teaching Mathematics through problem-solving" (TR 4 Interviewed data, 2020). One of the teachers further added that "identifying the correct procedure in solving a specific problem is a challenge of teaching Mathematics through problem-solving" (TR5 Interviewed data, 2020).

These excerpts suggest that most of the teachers did not incorporate problem-solving in their instruction probably since they did not know the principles and guidelines of problem-solving. None of them was able to give a guiding principle of problem-solving as well as describing how she/he incorporates it in her/his lesson.

The findings are in harmony with those findings by Matlala's (2015) that Mathematics teachers found it difficult to teach through problem-solving approaches and that the teachers still taught using the traditional approaches including storytelling and stepping in to show learners how to solve a mathematical problems. Furthermore, Buschman (2004) argued that teaching through problemsolving is a challenge to many teachers. One of the challenges mentioned was teacher educators' inability to prepare their students to teach Mathematics through problem-solving. The qualitative data from the interview also proved that public JHS Mathematics teachers in the Berekum West District "Moderately Used" problem-solving instructional strategies in their teaching. The interviewees were unable to describe how they used problem-solving instructional strategies in their teaching. They suggested that most of their classroom instructions were not always problembased.

Research Question 3: How do Mathematics Teachers engage pupils in Problem-Solving among public junior high schools in Berekum West district?

Research Question 3 sought to establish how Mathematics teachers engaged pupils in ProblemSolving. The response of teachers on the extent of students' engagement in problem-solving during the instructional process is presented in table 3: To accomplish this goal, mean scores were calculated under the following criteria: The mean of less than 2.50 indicated rarely engaged, between 2.50 and 3.50 indicated occasionally engaged and above 3.50 indicated always engaged.

Table 3: Descriptive Statistics on Pupils Engagement in Teaching Problem-Solving

\begin{tabular}{|c|c|c|c|}
\hline Kinds of Engagements & Mean & Std. Dev. & Levels of Engagement \\
\hline Use of Manipulates & 3.72 & 0.51 & Always Engage \\
\hline Active Engagement of Learners & 3.45 & 0.79 & Occasionally Engage \\
\hline Teacher as a Facilitator & 3.19 & 0.82 & Occasionally Engage \\
\hline Building Lessons on Learners RPK & 3.15 & 0.75 & Occasionally Engage \\
\hline Motivation & 3.15 & 0.83 & Occasionally Engage \\
\hline Application of Knowledge & 2.92 & 0.82 & Occasionally Engage \\
\hline Assessment & 2.60 & 1.00 & Occasionally Engage \\
\hline Curiosity & 2.60 & 0.90 & Occasionally Engage \\
\hline Perseverance & 2.19 & 0.85 & Rarely Engage \\
\hline Total Level of Engagements & 3.00 & 0.80 & Occasionally Engage \\
\hline
\end{tabular}


As table 3 indicates, Mathematics teachers' indicated to always engage learners with the use of manipulative $(M=3.72, S D=0.51)$, whereas active engagement of learners ( $M=3.45, S D=0.79)$, teacher as a facilitator $(M=3.19, S D=0.82)$, building lessons on learners RPK $(M=3.15, S D=0.75)$, motivation $(\mathrm{M}=3.15, \mathrm{SD}=0.83)$, application of knowledge $(\mathrm{M}=2.92, \mathrm{SD}=0.82)$, assessment $(\mathrm{M}=2.60, \mathrm{SD}=1.00)$ and curiosity $(M=2.60, S D=0.90)$ were occasionally used while perseverance $(M=2.19, S D=0.85)$ was rarely used. Generally, Mathematics teachers occasionally $(M=3.00, S D=0.80)$ engaged learners in all the kinds of engagement outlined in the study as problem-solving instructional techniques. According to Van de Walle (2007) and Florence (2012), Mathematics manipulatives can help engage students for a longer period by helping them stay focused on particular tasks. Florence feels that while lecture-based teaching might be tedious, manipulatives allow students to participate actively in their learning.

The following is how respondents expressed their views through interview: "I give them questions I believe they can manage to do and they perform" (TR 1, Interviewed data, 2020). Another respondent expressed that "I engage pupils in problem-solving by putting them in groups so that they can work together by sharing ideas and things to solve the problem" (TR 2, Interviewed data, 2020). It was also revealed that some "children dislike Mathematics and at times difficult questions might scare them from even coming to school and as you know, our system too...., So I give those questions I believe they can do" (TR 3, Interviewed data, 2020).

One more teacher made it clear that "I give them questions and I encourage them to follow the procedures I used to solve it. Even if it is difficult, I encourage them to reason well and at times some students will get the answer" (TR 4, Interviewed data, 2020). Other teachers implemented the goal "by allowing pupils to attempt problem-solving questions on their own" (TR 5, Interviewed data, 2020).

\section{Conclusions and Recommendations Conclusion}

It is concluded that Mathematics teachers' ability on problem-solving was fair, due to the established perceived knowledge. Teachers' knowledge and practices of problem-solving was moderate. The moderate knowledge and practice ensured that teachers applied the varied instructional techniques and strategies in the teaching and learning process. Teachers' engagement with pupils in problemsolving was occasional and moderate. The moderate engagement allowed teachers and pupils to enjoy mathematics lessons in the classroom.

\section{Recommendations}

It is recommended that mathematics teachers should adhere to continuous professional development organised by the Ministry of Education. This will help them to use modern problem-solving strategies effectively. Furthermore, Mathematics teachers need to be trained through workshops, seminars and conferences on how to rightly use problem-solving approaches. They should re-examine their old routine methods of applying the Polya's model and apply modern approaches to problem-solving teaching and learning so as to enhance teachers and pupils' active participation

\section{References}

Abel, J. P., Buff, C. L., \& Burr, S. A. (2016). Social media and the fear of missing out: Scale development and assessment. Journal of Business \& Economics Research (JBER), 14(1), 33-44.

Anderson, J.A. (2009). Mathematics curriculum development and the role of problem solving. ACSA, (pp. 1-8). Sydney.

Andrews, P., \& Xenofontos, C. (2014). Defining mathematical problems and problembeliefs in Cyprus and England. Mathematics Education Research Journal, 26(2), 279-299.

Bay, J. M. (2000). Linking problem-solving to student achievement in Mathematics: Issues and outcomes. Journal of School Improvement, 1(2), 8 - 13.

Bley, N. S., \& Thornton, C. A. (2001). Teaching Mathematics to students with learning disabilities. PRO-ED, Inc., 8700 Shoal Creek Blvd., Austin, TX 48757-6897.

Buschman, L. (2004). Teaching problem-solving in Mathematics. National Council of Teachers of Mathematics, 10(6), 302-309.

Cai, J., \& Lester, F. (2012). Research Brief. New York: Council of Teachers of Mathematics.

Creswell, J. W. (2009). Research design: Qualitative and mixed methods approach.London and Thousand Oaks: Sage Publications. 
Creswell, J. W. (2017). Research design: Qualitative, quantitative, and mixed methods approach. London: Sage publications.

Florence, H. (2012). The effects of Mathematics manipulatives. Retrieved September, 19, 2012 from http://www.ehow.com/info_80 40301_effects-Mathematics-manipulativ es .html.

Hiebert, J. (2003). Teaching mathematics in seven countries: Results from the TIMSS 1999 video study. Washington, DC: National Centre for Education Statistics, Institute.

Hiebert, J., \& Wearne, D. (2003). Developing understanding through problem-solving. Teaching Mathematics through problemsolving: Grades, 6(12), 3-14.

Kusi, H. (2012). Doing qualitative research: $A$ guide for researchers. Accra: Emmpong Press.

Lester Jr, F. K. (2013). Thoughts about research on mathematical problem-solving instruction. The mathematics enthusiast, 10(1), 245-278.

Mason, J. (2006). Mixing methods in a qualitatively driven way. Qualitative research, 6(1), 9-25.

Matlala, S. J. (2015). The experiences of secondary Mathematics teachers teaching Mathematics through problem-solving. A Thesis presented Graduate School: Stellenbosch University.

Mclntosh, R., Jarrett, D., \& Peixotto, K. (2000). Teaching mathematical problem-solving: Implementing the vision. Portland, Oregon: Mathematics and Science Education Center, North West Regional Laboratory.
Mereku, A. G. (2015). Assisting Ejura Presbyterian basic school students in solving linear equations in one variable using activity method. MPhil Thesis, University of Education, Winneba, Unpublished.

Morrison, K. (2012). School leadership and complexity theory. Routledge.

Polya G. (1945). How to solve it: $A$ new aspect of mathematical method. New Jersey: Princeton University Press.

Polya, G. (1954). Mathematics and plausible reasoning: Induction and analogy in mathematics (Vol. 1). Princeton University Press.

Roberts, A. L., M. D. Sharma, S. Britton, and P. B. New. "Identification and use of theoretical frameworks for a qualitative understanding of mathematics transfer." CAL-laborate International 17, no. 1 (2009): 1-14.

Tratton, P. R., \& Midgett, C. (2001). Learning through problems: A powerful approach to University of Minnesota. Retrieved on September 2021 from http://groups. physics.umn.edu/physed/People/charles.ht $\mathrm{m}$

Van de Walle, J. A. (2007). Designing and selecting problem-based tasks. Teaching mathematics through problem solving: Prekindergartengrade, 6, 67-80.

Webb, P., \& Sepeng, P. (2012). Exploring mathematical discussion in word problemsolving. Pythagoras, 33(1), 1-8. S 